\title{
POST-ELASTIC SEISMIC RESPONSE OF A REINFORCED CONCRETE FRAME
}

+W. R. Walpole and R. Shepherd

\section{Introduction}

The two-phase philosophy of structural seismic design involves the choice of a structural system which will remain elastic under small or medium earthquakes and which will deform inelastically, but not catastrophically, in a major seismic disturbance.

The normal mode, response spectrum concept has been widely used to satisfy the first part of the approach in which elastic responses of a proposed building are calculated and used in a subsequent member size check. The current New Zealand Code (1) is based on this concept, a design curve being specified from which the base shear may be derived providing that the natural period of the structure has been predetermined. The code design spectrum is an idealised version of a proportion reduced elastic response spectrum, the reduction being inadequately substantiated theoretically and only partially justified qualitatively on the basis of many buildings having survived earthquakes in which they must have collapsed completely had they responded purely elastically.

The availability of high speed computers and consequent developments in analysis techniques have only recently made possible the application of direct numerical integration procedures to the prediction of inelastic seismic behaviour of structures. In this approach a structure may be assumed to behav in a linearly elastic manner during a succession of small time intervals and the non-linear behaviour may be determined as the response of a sequence of successively differing systems. A digitised earthquake record may be used as the forcing function and aspects such as the possibility of a structure failing as a mechanism, the pattern of yielding within the structure, and the ability of members to endure imposed elastic and plastic deformation may be investigated.

The results of an investigation of the inelastic behaviour of a typical New Zealand reinforced concrete frame subjected to a strong motion earthquake are presented below.

X Assistant Engineer, Beca, Carter, Hollings \& Ferner, Consulting Civil \& Structural Engineers, Wellington.

XX Reader in Civil Engineering, University of Canterbury, Christchurch. 


\section{The structure analysed}

A single transverse frame of a 12 storey reinforced concrete open frame building designed to be constructed in Auckland, was analysed. The building is symmetrical in plan, with six bays in the longitudinal direction and two in the transverse, each floor having an area of $3600 \mathrm{sq} . \mathrm{ft}$. The properties of the frame analysed are given in Table 1. An outline of the elastic and elasto-plastic behaviour of this frame subjected to the 1940 El Centro earthquake, N-S component, follows.

\section{Elastic analysis}

A normal mode analysis was carried out to enable the seismic forces to be predicted from a response spectrum (2). The member stiffnesses were estimated from the gross concrete sections taking the modulus of elasticity as $4.0 \times 10^{6} \mathrm{lb} / \mathrm{in}^{2}$; the lateral flexibility matrix being calculated by a computer program (3) which considered bending and shear deformations and the effect of rigid joints of finite size. The seismic forces were predicted by taking the root mean square of the modal responses found using the response spectrum curve assuming 10\% critical damping. The member actions caused by these predicted forces were found and are presented in Figure 2 together with the lateral forces. The normal mode properties and predicted response are listed in Table 2.

The elastic response to the El Centro record was found by integrating the modal equations of motion and summing the responses at each increment assuming 10\% damping. The variation of the displacement of the floors with time is shown in Figure 3 and the maximum floor displacements are plotted in Figure 2. A static analysis was also carried out to determine the member actions under the lateral loading required by the N.Z. code NZSS 1900 Chapter 8(1). Lateral loads were found using a coefficient of .065 on the base shear, as required for a private building of fundamental period 0.74 secs constructed in zone $\mathrm{C}$, and were distributed as required by the code, i.e., in approximately triangular fashion.

The lateral loads, deflections and member actions derived from this code are compared with those predicted from the dynamic elastic response in Figure 2. A factor of 5.7 is needed to reduce the predicted elastic response to the code figures comparing base shear values. 


\section{Elasto-plastic analysis}

The elasto-plastic response of the 12 storey 2 bay frame to the EI Centro record was found using a computer program (3) assuming ideal elasto-plastic behaviour of the members (see figure 1) and 10\% of critical damping in the first two modes. The ultimate moments of the members were assigned using a load factor of 1.25 on the NZSS code lateral,

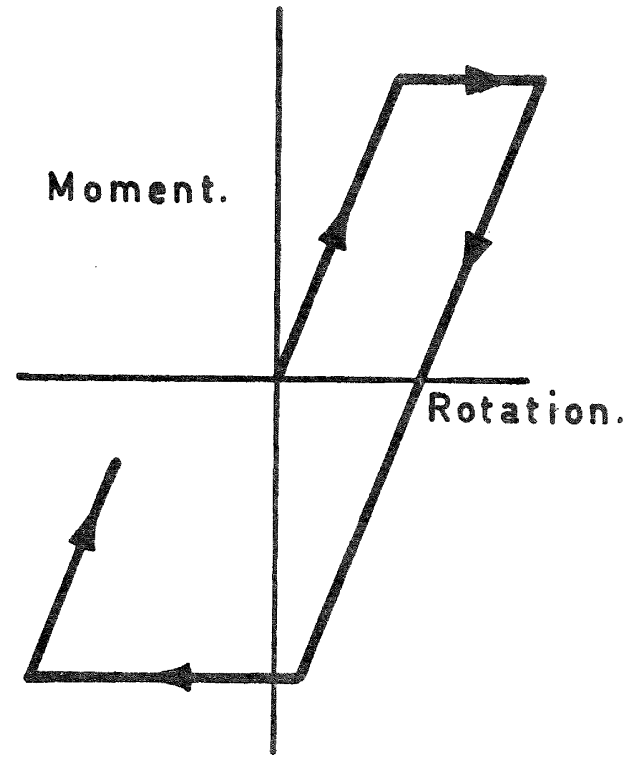

\section{FIGURE 1. Idealised Elasto- Plastic Behaviour.} dead and seismic live loads for the beams and a load factor of 1.50 for the columns. The relationship of the yield moments to the predicted elastic seismic moments and the moments under code lateral load is illustrated in Figure 2.

The variation of the displacement of the floors is plotted against time in Figure 4. The maximum displacements assuming elastic action are compared with those assuming elastoplastic action in Figure 2. The plastic action reduces the top storey deflection slightly, but the maximum displacement of the lower half of the frame is significantly increased. The displacement curves show a similar behaviour to two other reinforced concrete frames considered. The plastic action increases the magnitude of the first major peak at 1.90 secs, when the first yielding occurs, but reduces the magnitude of the following peaks. The response of this building differs from others examined(3) in that a major peak occurs at 5.40 secs when a large part of the plastic deformation in varicus members occurs. There is also a slight increase in the periodicity of motion.

The variation of the bending moment in a beam and column member is shown in Figure 5 with the growth of plastic deformation in each member plotted under the bending moment curve. After the increase in plastic deformations which occurs at 5.40 secs, a significant amount of permanent set is evident, totalling approximately 1.5 inches at the top floor.

The major part of the yielding occurs in the beam members with a maximum ductility factor of 7.01 in the first floor beam. A large ductility was also required at the base of the bottom column with a maximum of 9.48. The next largest column ductility, of 2.01, occurs just above the second floor.

It would appear for this frame that except for the bottom columns the plastic deformation has been largely restricted to the beams by making these members relatively weaker than the columns. The ductility ratio of the beam members is compared to the ratio of the 
maximum moment assuming elastic response to the yield moment in Figure 2. It can be seen that there is a pronounced tendency for the ductility requirements to be largest in the members with the highest moment ratio and for the members with a high moment ratio to require a ductility greater than the moment ratio.

\section{Comment on results}

Quite large ductilities were obtained near the bottom of the building, particularly at the base of the bottom columns, where a ductility of 9.48 was required. This was also the position of the highest moment ratio even though the columns were designed with a higher load factor than the beams. This is because the base of the bottom column is not affected very much by vertical loading whereas with the lower beams the vertical loading is more significant. It would appear from the limited studies made so far both here (3) and overseas (4) that a reinforced concrete frame with relatively slender members is liable to require higher member ductilities than either a flexible steel structure or a spandrel beam type of frame.

\section{Acknowledgements}

The work described formed part of that undertaken by the first author, in the course of his Ph.D studies, under the supervision of the second author.

The first author was supported throughout his graduate studies by a New Zealand University Grants Comittee Postgraduate Scholarship.

\section{Reterences}

(1)

New Zealand Standards Institute: Basic Loads to be used in Design and their Method of Application. NZSS 1900, Standard Model Building Bylaw. Chapter 8, 1965.

(2) Skinner, R.I. Earthquake Generated Forces and Movements in Tall Buildings. New Zealand D.S.I.R. Bulletin 166, 1964.

(3) Walpole, W.R. Unpublished Ph.D. Thesis, University of Canterbury N.Z. 1968.

(4) Clough, R.W., Benuska, K.I., and WiIson, E.L. Inelastic Earthquake Response of Tall Buildings. Proc. 3rd. W.C.E.E. New Zealand, 1965. 
TABLE 1

FRAME PROPERTIES

\begin{tabular}{|c|c|c|c|c|c|c|}
\hline Floor & $\begin{array}{l}\text { Column } \\
\text { Length } \\
\text { (inches) } \\
\end{array}$ & $\begin{array}{l}\text { Column } \\
\text { Dimension } \\
\text { (inches) }\end{array}$ & $\begin{array}{c}\text { Column } \\
\text { I }{ }^{4} \text { ) } \\
\text { (inches }^{2}\end{array}$ & $\begin{array}{l}\text { Beam } \\
\text { Dimension } \\
\text { (inches) }\end{array}$ & $\begin{array}{c}\text { Beam } \\
\begin{array}{c}\text { I } \\
\left(\text { inches }^{4}\right)\end{array} \\
\end{array}$ & $\begin{array}{l}\text { Floor } \\
\text { Weight } \\
\text { (Kips) } \\
\end{array}$ \\
\hline 12 & & & & $12 \times 24$ & 13,824 & 32.2 \\
\hline & 132 & $14 \times 14$ & 3,200 & & & \\
\hline 19 & & & & $12 \times 30$ & 27,000 & 76.4 \\
\hline & 142 & $18 \times 18$ & 8,750 & & & \\
\hline 10 & & & & $12 \times 30$ & 27,000 & 79.8 \\
\hline & 142 & $20 \times 20$ & 13,333 & & & \\
\hline 9 & & & & $12 \times 30$ & 27,000 & 86.7 \\
\hline 8 & 142 & $20 \times 20$ & 13,333 & $12 \times 36$ & 46,656 & 90.5 \\
\hline & 142 & $24 \times 24$ & 27,648 & & & \\
\hline 7 & 142 & $24 \times 24$ & 27,648 & $12 \times 36$ & 46,656 & 95.6 \\
\hline 6 & 142 & $24 \times 24$ & 27,648 & $12 \times 36$ & 46,656 & 95.6 \\
\hline 5 & 142 & $24 \times 24$ & 27,648 & $15 \times 36$ & 58,320 & 103 \\
\hline 4 & 142 & $27 \times 27$ & 44,280 & $15 \times 36$ & 58,320 & 103 \\
\hline 3 & 142 & $27 \times 27$ & 44,280 & $15 \times 36$ & 58,320 & 108 \\
\hline 2 & 142 & $27 \times 27$ & 44,280 & $18 \times 36$ & 69,984 & 108 \\
\hline $\begin{array}{c}1 \\
\text { BASE }\end{array}$ & 163 & $27 \times 27$ & 44,280 & $18 \times 36$ & 69,984 & 115 \\
\hline
\end{tabular}

All beams 268 inches long. 


\section{TABLE 2}

\section{NORMAL MODE PROPERTIES}

Mode 1

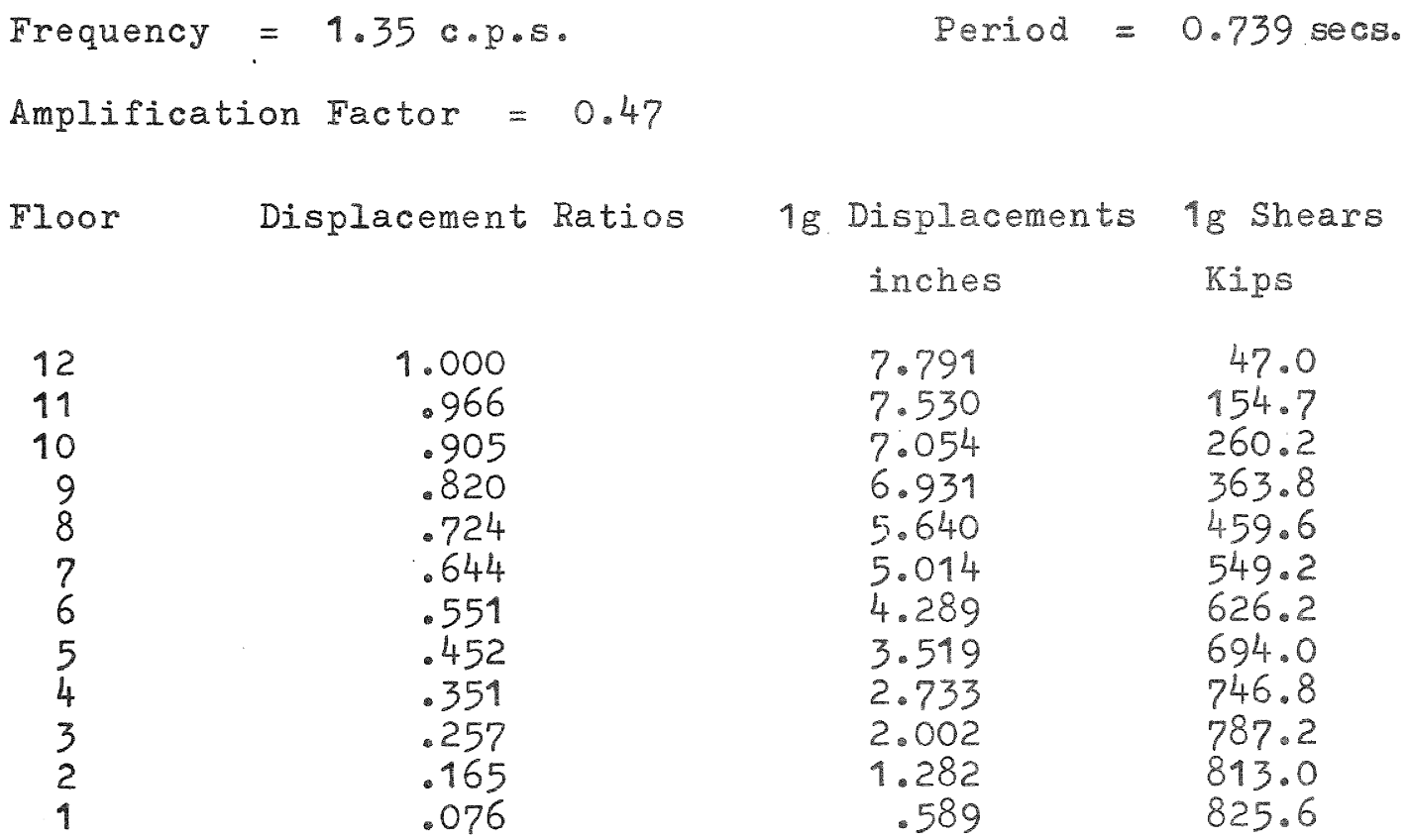

Mode 2

Frequency $=3.38$ c.p.s. Period $=2.96$ secs. Amplification Factor $=0.72$

Displacement Ratios

$\begin{array}{rr}12 & 1.000 \\ 11 & .800 \\ 10 & .480 \\ 9 & .107 \\ 8 & -.227 \\ 7 & -.411 \\ 6 & -.532 \\ 5 & -.577 \\ 4 & -.540 \\ 3 & -.445 \\ 2 & -.309 \\ 1 & -.148\end{array}$

$1 \mathrm{~g}$ Displacements $1 \mathrm{~g}$ Shears inches Kips

$-.635$

$-.508$

$\ldots .305$

. .068

.144

.261

.338

.367

.343

.283

.196

.094
$-23.9$

$-69.2$

$-97.6$

$-104.5$

$-89.2$

$-60.1$

21.7

62.9

98.4

123.0

135.6
$-22.4$ 


\section{TABLE 2 continued}

\section{Mode 3}

Frequency $=5.62 \mathrm{c} . \mathrm{p} . \mathrm{s}$.

Period $=0.178$ secs.

Amplification Factor $=0.64$

Floor

Displacement Ratios

1g Displacements

$1 g$ Shears

$\begin{array}{rr}12 & 1.000 \\ 11 & .489 \\ 10 & . .113 \\ 9 & -.548 \\ 8 & -.650 \\ 7 & -.466 \\ 6 & -.118 \\ 5 & .251 \\ 4 & .504 \\ 3 & .571 \\ 2 & .474 \\ 1 & .250\end{array}$

Inches

$$
.1536
$$$$
.0751
$$$$
-.0174
$$$$
-.0841
$$$$
-.0998
$$

$-.0716$

$-.0181$

.0386

.0774

.0876

.0729

.0384
Kips

15.96

34.46 30.00

6.49

$-22.68$

$-44.76$

$-50 \cdot 34$

$-37.52$

$-11.78$

18.65

43.96

58.22

\section{PREDICTED ELASTIC RESPONSE}

$\begin{array}{cccc} & \text { Displacement } & \text { Shears } & \text { Forces } \\ & \text { inches } & \text { Kips } & \text { Kips } \\ 12 & & & \\ 11 & 3.743 & 30.0 & 30.04 \\ 10 & 3.607 & 91.8 & 61.70 \\ 9 & 3.369 & 143.9 & 52.12 \\ 8 & 3.047 & 189.1 & 45.22 \\ 7 & 2.691 & 228.6 & 39.64 \\ 6 & 2.397 & 266.8 & 38.18 \\ 5 & 2.058 & 300.6 & 33.66 \\ 4 & 1.698 & 332.0 & 31.42 \\ 3 & 1.327 & 358.8 & 26.84 \\ 2 & .978 & 382.0 & 23.10 \\ 1 & .629 & 398.4 & 16.51 \\ & .290 & 407.2 & 8.72\end{array}$



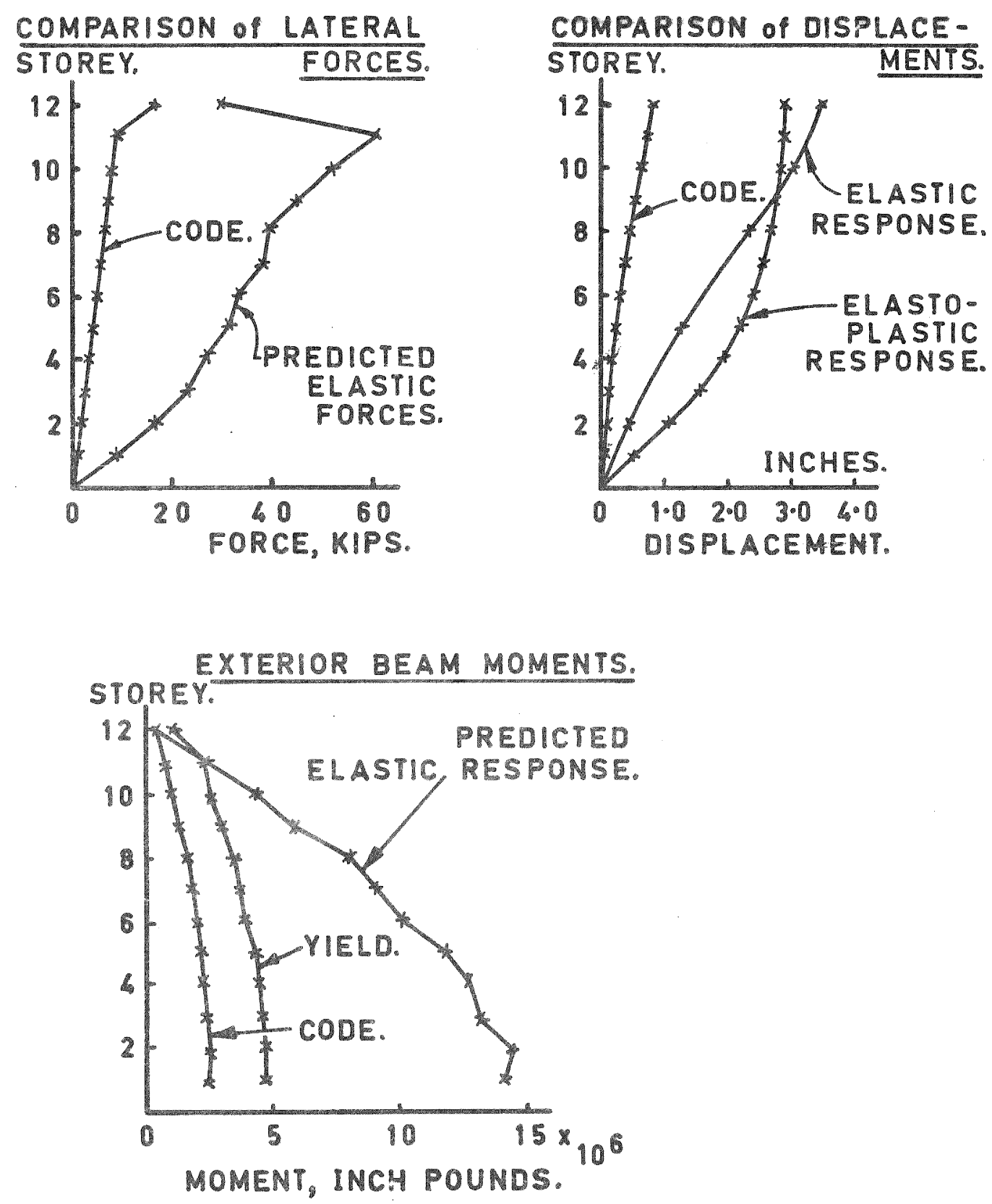

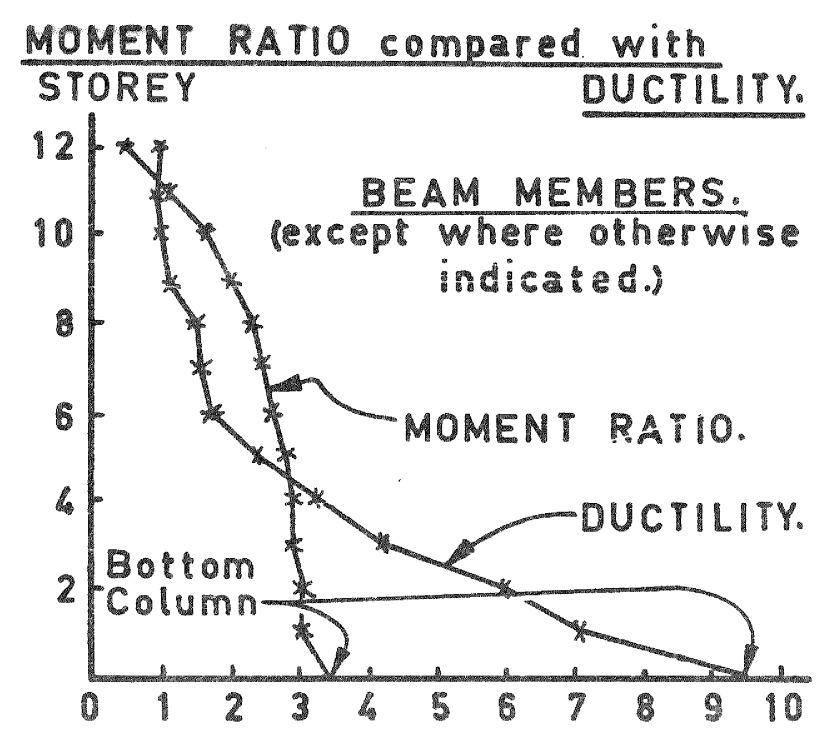

EXTERIOR COLUMN MOMENTS.

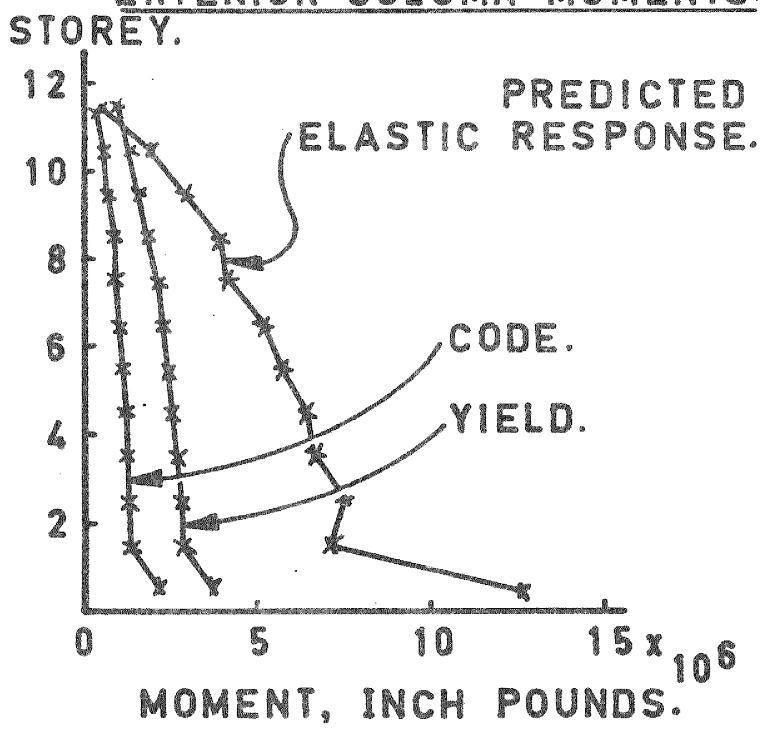

FIGURE 2

홍 
$\vec{\partial}$

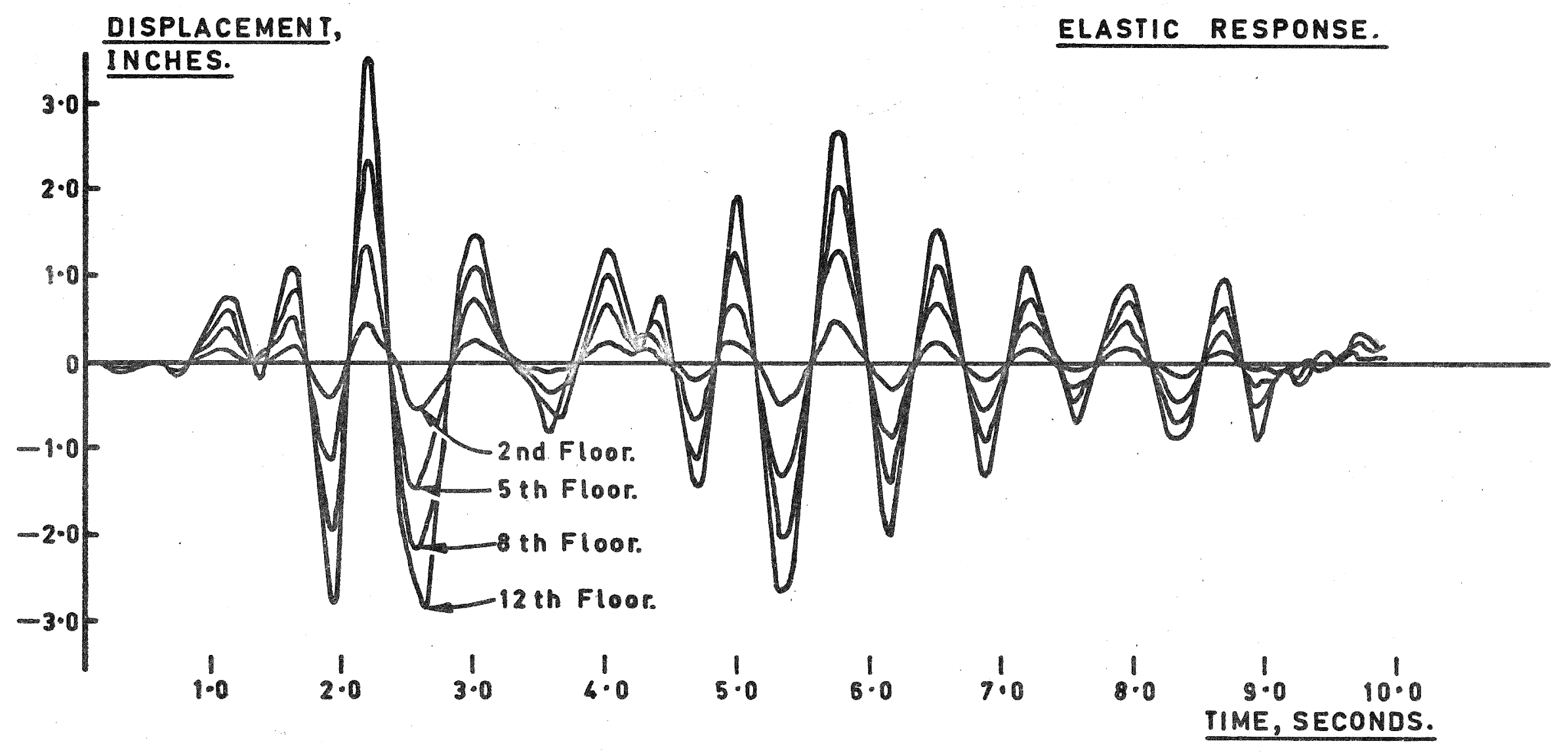

FIGURE 3 


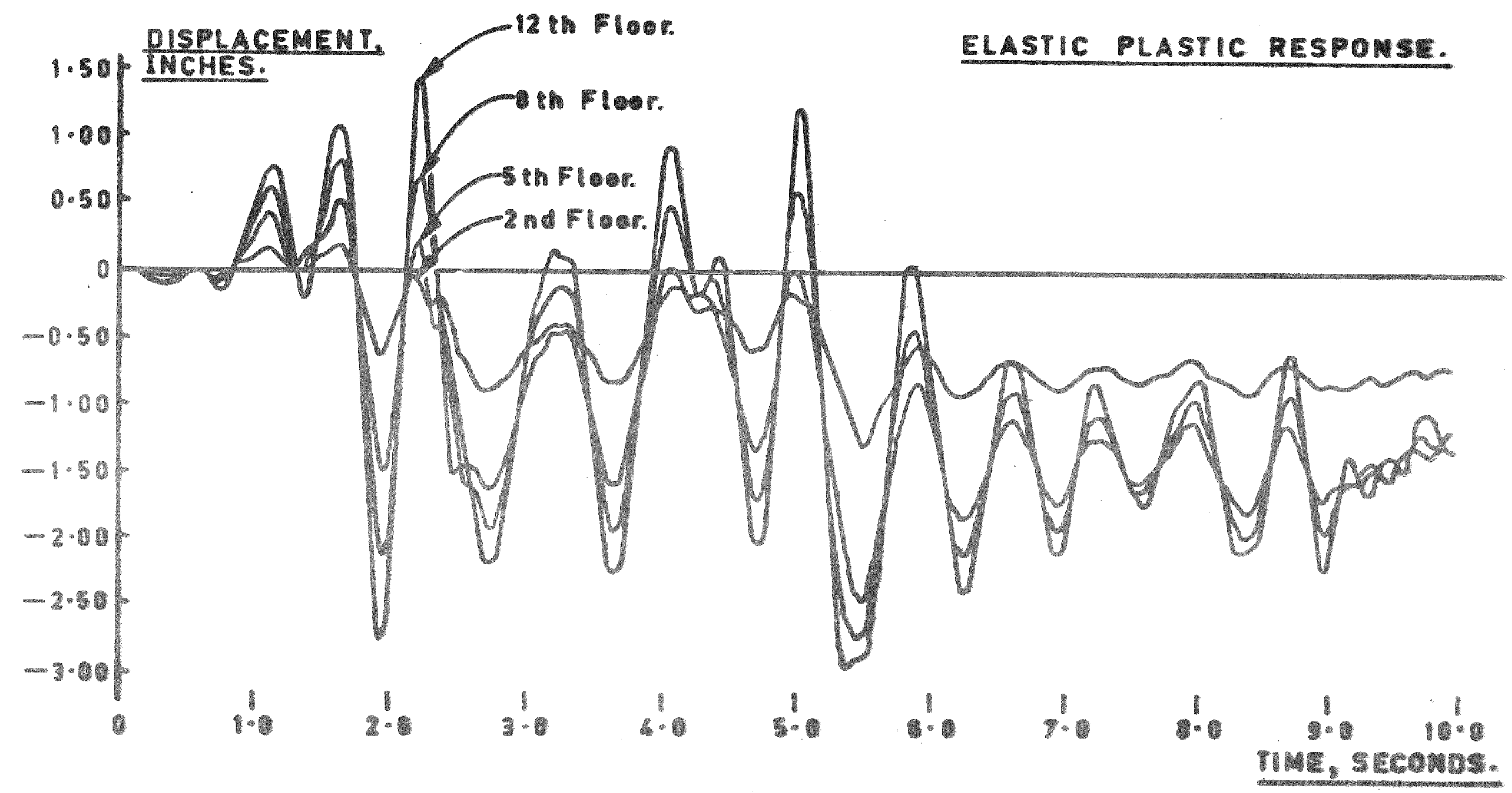

FIGURE 4 


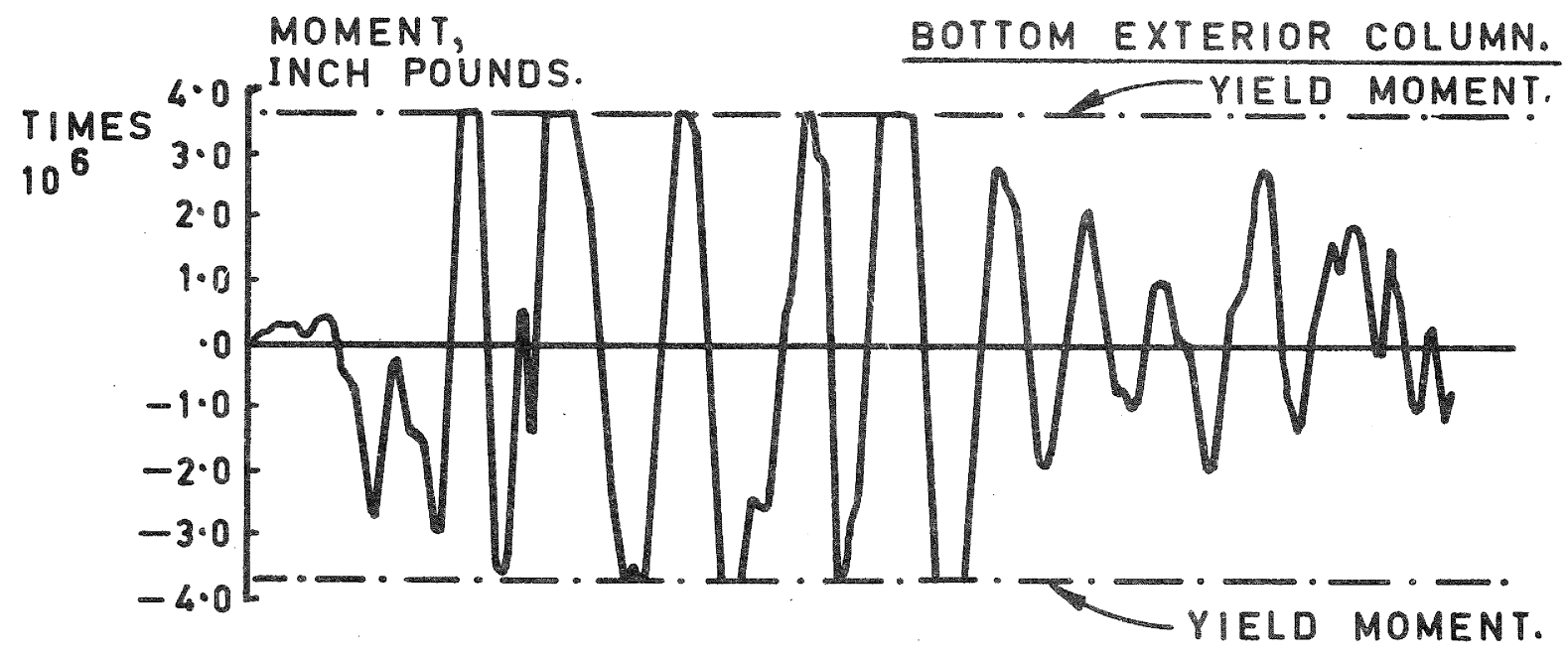

PLASTIC DEFORMATION.
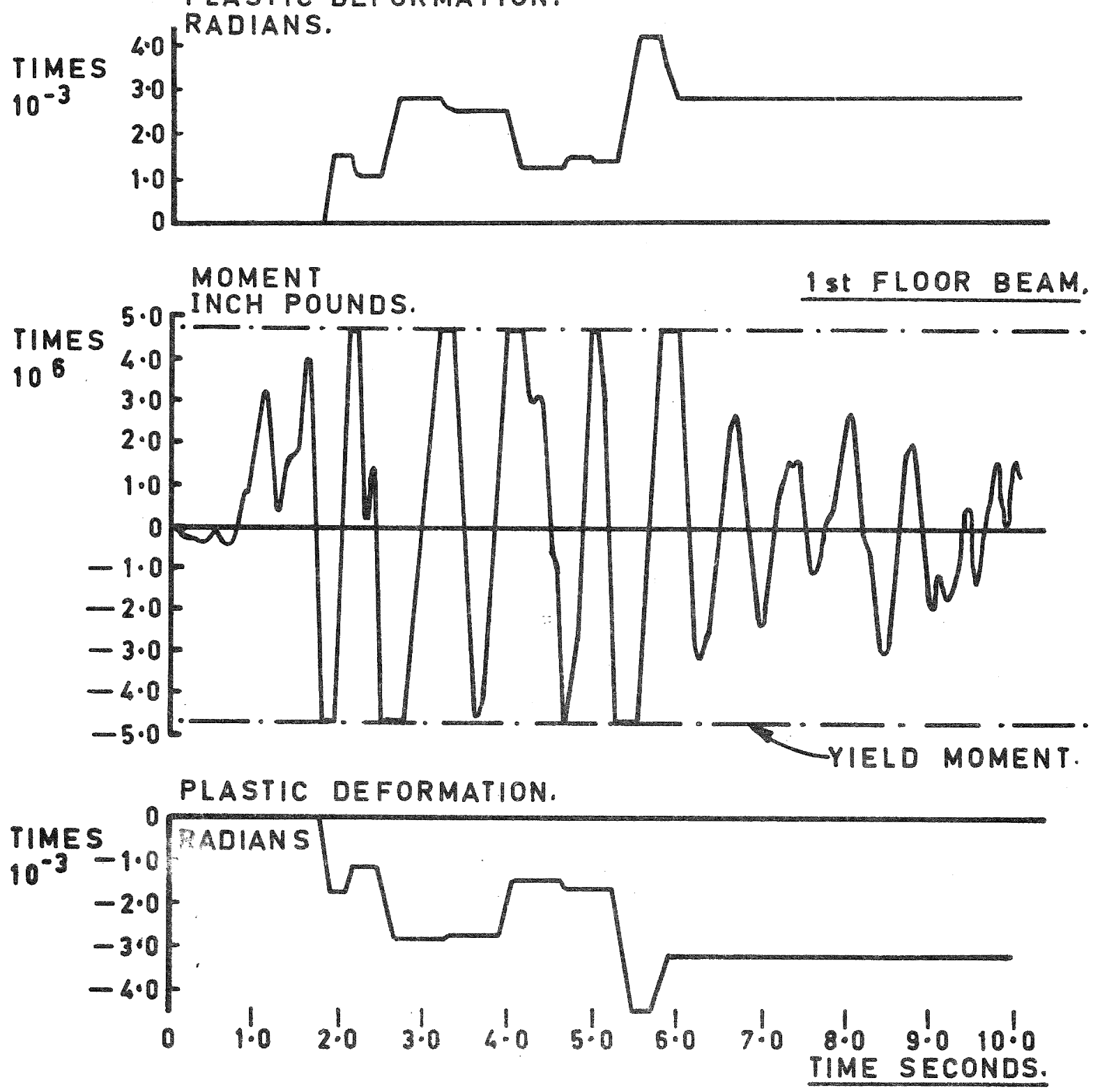

FIGURE 5 